\title{
Differentiation of Species of the Baccharis Genus by HPLC and Chemometric Methods
}

\author{
Audrey A. S. G. Lonni, Ieda S. Scarminio, ${ }^{\dagger}$ Lucas M. C. Silva, and Dalva T. Ferreira \\ Departamento de Química, Universidade Estadual de Londrina, Caixa Postal 6001, CEP 86051-970, \\ Londrina, Paraná, Brazil
}

\begin{abstract}
Phytochemical investigation of the aerial parts of three Baccharis species (Asteraceae family) was performed using HPLC and chemometric methods, with the objective of distinguishing between three morphologically very similar species: Baccharis genistelloides Persoon var. trimera (Less.) DC, B. milleflora (Less.) DC and B. articulata (Lam.) Persoon. With the help of Principal Component Analysis (PCA) and variance weights, it was possible to characterize the chromatographic profiles of the alcoholic extracts of the three species. Application of Soft Independent Modeling of Class Analogy (SIMCA) and K-Nearest Neighbor (KNN) methods on a training set of 74 extracts resulted in models that correctly classified all eight samples in an independent test set.
\end{abstract}

(Received February 4, 2003; Accepted April 14, 2003)

\section{Introduction}

Species of Baccharis (Asteraceae) are popularly known as "carqueja" in Brazil. The Baccharis genus, existing in Brazil, is represented by several species that have three-winged branches in common. This group of native plants is common in southern Brazil as well as in Uruguay, northern Argentina, Paraguay and Bolivia. In traditional medicine they are used in the form of tea for gastrointestinal treatments, ${ }^{1}$ for liver diseases, ${ }^{2}$ as antirheumatic agents, ${ }^{3}$ and to treat inflammatory processes, among other applications. ${ }^{4}$ "Carqueja" tea is prepared from dried complete, fragmented or ground branches, and is readily purchased in pharmacies and supermarkets in Brazil. There are estimated to be around 400 species, of which no more than 50 have been studied. Differentiation between three-winged species is complex; for example, $B$. cylindrica, $B$. myriocephala, $B$. milleflora and $B$. crispa are especially similar to $B$. trimera, so that certain authors actually consider them to be identical with $B$. trimera.

The use of chemical analysis in chemotaxonomy has been restricted to the development of specialized methods to isolate specific compounds. ${ }^{5}$ On the other hand, chemosystematic has combined the use of chemical multivariate mathematical and statistical methods on biological systems with special emphasis on the solution of taxonomic characterization. ${ }^{5}$ Chemometric methods, ${ }^{6-10}$ among them principal component and hierarchical cluster analyses, have been applied in chemosystematic and taxonomic studies of different plants. Fourier transform microscopy in combination with chemometric classification methods, like Soft Independent Modeling by Class Analogy (SIMCA) and the K-Nearest Neighbor classification rule $(\mathrm{KNN})$, were investigated as new methods to discriminate cyanobacterial strains. ${ }^{11}$

In this work, a phytochemical investigation of the aerial parts

$\dagger$ To whom correspondence should be addressed.

E-mail: ieda@qui.uel.br of three species of the Baccharis genus of the Asteraceae family was performed using high performance liquid chromatography and chemometric methods. The objective was to develop a taxonomic identification process that is fast and accurate without the necessity of adding specific information of biological origin. This can become a powerful chemotaxonomic tool for morphologically similar species that are difficult to characterize by conventional means. Three Baccharis species, B. genistelloides Persoon var. trimera (Less.) DC, (Tr), B. milleflora (Less.) DC, (Mf), and B. articulata (Lam.) Persoon, (Ar) were donated for this study.

\section{Experimental}

\section{Plant material}

Three types of plants: Baccharis trimera (Less.) DC, and $B$. milleflora (Less.) species, as well as an uncharacterized species, were cultivated in the experimental garden of the Departamento de Química of the Universidade Estadual de Londrina (UEL), in Londrina, PR, Brazil. The samples from these cultivated plants were denominated as Tr, Mf and Ds, respectively. The fourth species, B. articulata (Lam.) Persoon cultivated in the experimental garden of the Instituto Agronômico do Paraná (IAPAR), Londrina, furnished samples denominated as Ar.

Vouchers of the four species were deposited in the Herbarium of the Universidade Estadual de Londrina. The origins of the cultivated plants as well as their Herbarium access numbers are given in Table 1.

\section{Collection and drying}

Collections were performed weekly from August 2001 to February 2002. Aerial parts of the plants were collected, avoiding material containing flowers or damaged by insects or fungus, and cut into small pieces to permit homogeneous chemical sampling. Drying was carried out at ambient temperature for nine days, with the samples protected from light, humidity and insect and fungus attacks. 
Table 1 Origin of cultivated plants and their access numbers of the herbarium of the Universidade Estadual de Londrina

\begin{tabular}{clll}
\hline Sample & \multicolumn{1}{c}{ Species } & Origin and distance from Londrina & \multicolumn{1}{c}{ Access number } \\
\hline Mr & B. milleflora $\left(\right.$ Less.) DC ${ }^{\mathrm{a}}$ & Maringá $(100 \mathrm{~km})$ & A.A.S.G. Lonni 1 FUEL 31.517 \\
$\mathrm{Tr}$ & B. trimera $($ Less.) DC & Rolândia $(20 \mathrm{~km})$ & A.A.S.G. Lonni 2 FUEL 31.518 \\
$\mathrm{Ds}$ & B. trimera $($ Less.) DC & São Paulo $(530 \mathrm{~km})$ & A.A.S.G. Lonni 3 FUEL 31.519 \\
$\mathrm{Ar}$ & B. articulata $(\text { Lam. })^{\mathrm{d}}$ & Londrina & A.A.S.G. Lonni 4 FUEL 31.958 \\
& Persoon & &
\end{tabular}

a. Dr. Gert Hatschback. b. Dr. Leo A. Schoof. c. Olinda Leites Bueno. d. Dr. Walter Kranz.

\section{Extract preparation}

Aerial parts of the dried and green plants (11.8 g) were extracted for $5 \mathrm{~min}$ with a food processor after addition of 250 $\mathrm{ml}$ of technical grade and absolute ethyl alcohol, respectively. The solutions remained at rest for $24 \mathrm{~h}$. The ethanolic extracts were filtered and concentrated in a rotary evaporator at a temperature less than $100^{\circ} \mathrm{C}$. The procedure was repeated three times, after which time extracts were placed in an oven at $37^{\circ} \mathrm{C}$.

\section{Chromatographic analysis}

Eluent selection, as well as sample preparation for HPLC analysis, should be performed in a planned way since it plays a fundamental role in separating plant substances. If done without criterion, this selection can cause significant wastes of time and reagents in the laboratory, besides leading to unsatisfactory results. In this work, these conditions were chosen using TLC, since it is a simple and fast technique.

\section{Thin layer chromatography assay}

Thirty milligrams of dried extract were re-dissolved in a mixture of $2 \mathrm{ml}$ of ethyl alcohol, $0.1 \mathrm{ml}$ of water and $0.2 \mathrm{ml}$ of dichloromethane. The chromatograms were run in normal phase silica gel with fluorescein indicator. The mobile phase and the solvent for sample preparation were chosen by means of a simplex-centroid design, ${ }^{12}$ with three additional mixture points, 8, 9 and 10, totaling 10 mixtures, Fig. 1. The hexane, methanol and dichloromethane eluents were chosen using a polarity scale. The 1,2 and 3 vertex points of the design correspond to pure eluents: hexane, methanol, and dichloromethane, respectively. The 4,5 and 6 points on the sides, are 1:1 binary mixtures of the eluents, 1 and 2, 2 and 3 and 1 and 3 . Point 7 is a ternary mixture with equal parts of all three eluents. The 8,9 and 10 points correspond to eluent mixtures in the $1: 1: 4,1: 4: 1$ and $4: 1: 1$ proportions.

The developments were carried out with ultraviolet irradiation.

\section{Sample preparation for HPLC}

Each sample was prepared by weighing $30.0 \mathrm{mg}$ of concentrated extract and re-dissolving it in $3 \mathrm{ml}$ of dichloromethane, leaving it at rest for $1 \mathrm{~h}$ and later filtering through common filter paper. Then dilution of $50 \mu \mathrm{l}$ of this solution in $950 \mu \mathrm{l}$ of methanol was done. The resulting solution was filtered twice with a $0.45 \mu \mathrm{m}$ Millipore filter.

\section{HPLC analysis}

Analyses were carried out using a Shimadzu Model LC-10AD chromatograph with an SPD-M10AVP diode array detector, having as chromatographic conditions, methanol eluent (J. T.

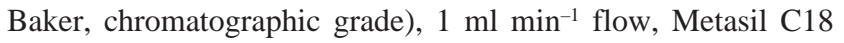
ODSPN 0380 Metachem $(250 \times 4.6 \mathrm{~mm})$ column, $5 \mu \mathrm{m}$ particle size. The temperature was fixed at $35^{\circ} \mathrm{C}$. The injection volume was $20 \mu \mathrm{l}$ and elution was monitored at $254 \mathrm{~nm}$.

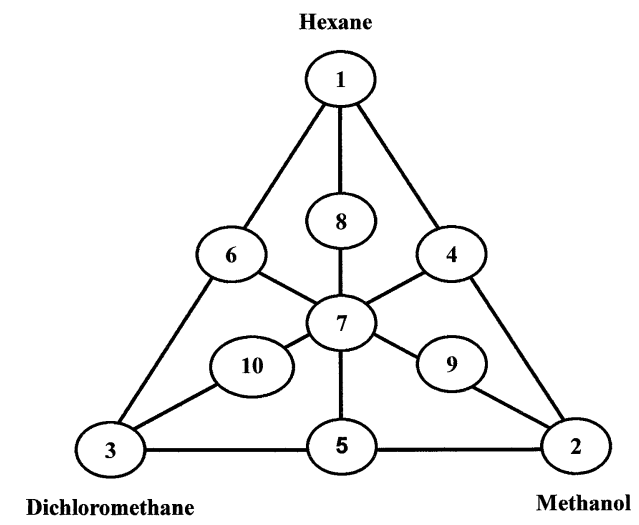

Fig. 1 Illustration of the modified simplex-centroid mixture design.

\section{Chemometric Methods}

\section{Principal component analysis (PCA)}

In PCA the original variables (characteristics) are transformed into new variables that are linear combinations of the original ones. The objective of this method is to reduce the data dimensionality, but it can also be used to construct classification models. ${ }^{13}$

\section{Variance weights}

These weights determine the individual importance of each variable or characteristic in the discrimination between each pair of classes. The variance weight for a variable is calculated by dividing the interclass variance for a pair of classes by the sum of their intraclass variances. ${ }^{14}$

\section{K-Nearest neighbor analysis (KNN)}

This classification method uses as a decision criterion the distance between the samples. Samples are classified into classes that correspond to the classes of their nearest neighbors. ${ }^{15}$ The Euclidean distance was used in this study.

\section{Soft independent modeling by class analogy (SIMCA)}

This method classifies samples based on their similarities to principal component models. The data of the training set are used to determine principal component models for each class. One of the ways of determining the appropriate number of principal components is to use the cross-validation technique. ${ }^{15}$ The classification of test set samples is obtained by adjusting each of these samples to each model and deciding, at the $95 \%$ confidence level, if the sample belongs to the corresponding class or not. 


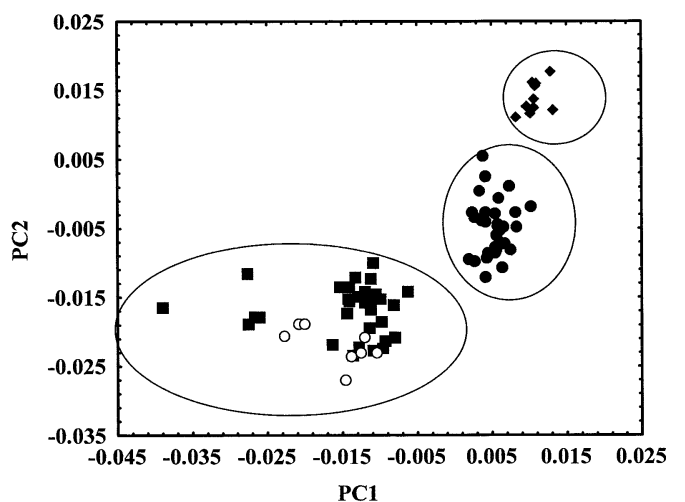

$\begin{array}{ll}- & \text { Mf } \\ - & \mathbf{T r} \\ - & \mathbf{A r} \\ \circ & \mathbf{D s}\end{array}$

Fig. 2 PC1 vs. PC2 score graph of the Tr, Mf, Ar and Ds samples, obtained from the extracts of dried and fresh plants, accounting for $65.0 \%$ of the total data variance.

\section{Computer programs}

The computational program, ARTHUR, modified for microcomputers ${ }^{16}$ was used for the SIMCA, KNN and variance weight calculations. For the PCA and pre-processing calculations, FORTRAN programs developed in our laboratory were used on PC type computers.

\section{Results and Discussion}

The TLC results showed that dichloromethane separates a larger number of substances from the extracts, whereas methanol provides the poorest elution. Considering that normal phase silica gel is more polar than the stationary phase of the $\mathrm{C}_{18}$ column, we chose pure methanol as the mobile phase and we did extract re-dissolutions using dichloromethane.

\section{Taxonomic analysis}

The vouchers of the cultivated three-winged species, Mf, $\mathrm{Tr}$ and Ds, were sent to the Zoobotanical Foundation of Rio Grande do Sul state for new taxonomic characterization. The results confirmed the difficulty of classifying them based on conventional taxonomic techniques, since all three collections were classified as Baccharis genistelloides Persoon var. trimera (Less.) DC. The Ar species was not sent for new characterization since, being bi-winged, it is easily discriminated from the three-winged species.

\section{The data matrix}

The data set contained 82 samples. Each sample was represented by 619 height values of the chromatographic peaks, resulting in an $82 \times 619$ matrix. For applications using the KNN and SIMCA methods and the variance weights, this matrix was divided into two sets: one for training and the other for testing the training set results. The training set was composed of 74 samples obtained from fresh and dried plants. This set was divided into three classes, one for each species: Mf, Tr and Ar. The test set was made up of eight samples of the Ds species, taxonomically denominated as $B$. trimera, also obtained from the extracts of green and dried plants.

\section{Chemometric analysis}

Before the chemometric analysis, the data were pre-processed. Different pre-processing methods were used. ${ }^{15}$ In this application five kinds of pre-processing techniques were tested:

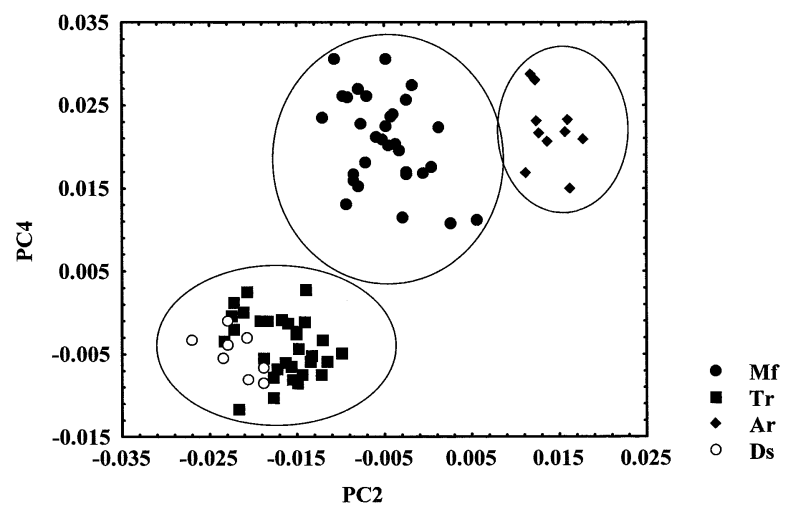

Fig. 3 PC2 vs. PC4 score graph of the Tr, Mf, Ar and Ds samples, obtained from the extracts of dried and fresh plants, accounting for $28.8 \%$ of the total data variance.

normalization to unit area, normalization to the unitary vector, autoscaling, area normalization followed by autoscaling and data centering about the average. The best results were obtained by unit area normalization.

The data set with 82 samples normalized to unit area was subjected to PCA. The first five components explain $81 \%$ of the total data variance. Figure 2 shows a graph of the scores of the first two principal components that explain $65 \%$ of the statistical variance in the data. The projection is a twodimensional representation of the 619 dimensions. The graph shows that the first principal component, PC1, discriminates the Tr and Ds samples from those of the Mf and Ar species, whereas PC2 discriminates Mf from Ar.

Figure 3 shows the score graph of PC2 versus PC4, with an accumulated variance of $28.8 \%$. As in Fig. 2, we can identify three groups: two located on opposite sides of PC2, $\mathrm{Tr}$ and $\mathrm{Ar}$, and one intermediate group, Mf. Furthermore, PC4 discriminates Tr and Ds from Mf and Ar, as does PC1. In this graph the test set samples, Ds, are seen to have the same characteristics as the Tr species, as expected, since the samples were taxonomically characterized as $B$. trimera.

These was no species discrimination by PC3 and PC5. Also none of the principal components discriminated between green and dried plants. As seen in Figs. 2 and 3, the Tr samples have PC2 scores with opposite signs to those of the Mf and Ar samples. This contrast can be explained with the help of Figs. 4 and 5. Figure 4 shows a graph of the loading values on PC2 versus retention time. Positive values are situated in four regions between: 1.4 and 2.6, 4.0 and 4.4, 5.0 and 5.7 and 7.0 and $8.0 \mathrm{~min}$. From Fig. 5 it is possible to verify that in these regions the analytical signals for $\mathrm{Ar}$ and $\mathrm{Mf}$ are more intense than those of $\mathrm{Tr}$, and for the Ar and Mf samples have positive scores.

Figure 4 also shows that two regions present negative values, one situated around 2.6 to 4.0 and the other from 4.4 to $5.2 \mathrm{~min}$. In Fig. 5, one can verify that in the 2.6 to 4.0 interval the most intense analytical signals belong to samples of the $\operatorname{Tr}$ species. For this reason the $\operatorname{Tr}$ species samples have negative PC2 scores.

These results suggest that the characteristics responsible for the discrimination between $\mathrm{Mf}, \mathrm{Tr}$ and $\mathrm{Ar}$ are more polar substances and present peaks with retention times around 1.7, 2.5 and $2.7 \mathrm{~min}$, respectively.

The SIMCA and KNN classification methods were employed for qualitative discrimination of the three species. In 


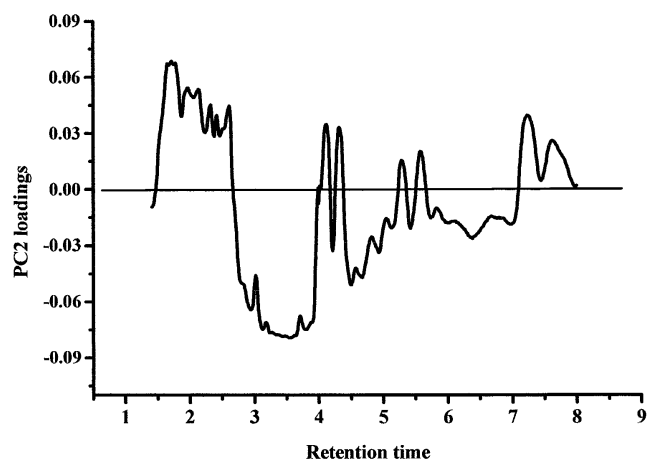

Fig. 4 PC2 loadings graph. PC2 explains $23.7 \%$ of the total data variance.

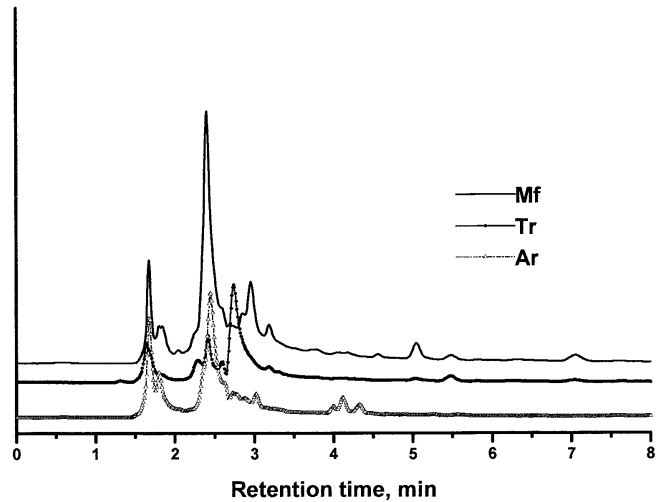

Fig. 5 Original chromatograms of the $\mathrm{Tr}$, Mf and $\mathrm{Ar}$ species obtained from the extracts of the fresh plant.

classification, the objective is to develop a model for each class in the training set that can be used to classify samples of the test set. SIMCA was used to construct a PCA model for each class: Mf, $\operatorname{Tr}$ and Ar, with the aim of testing these models for the classification of the samples of the Ds species. The number of PC's used in the modeling was determined by cross validation. All three models, one for each species, had two PC's. With this model, $100 \%$ of the training and test set samples were correctly classified.

For the KNN method, the training and test set samples were classified $100 \%$ correctly using 10 nearest neighbors.

With the objective of determining the best discriminatory region, two regions of the chromatogram were investigated separately: one for the retention time interval of 1.4 to $3.7 \mathrm{~min}$, and another from 3.8 to $7.8 \mathrm{~min}$. The SIMCA and KNN results confirmed that the region between 1.4 and 3.7 min differentiates the three species, correctly classifying all the Tr, Mf, Ar and Ds samples. This encouraged us to find the characteristics most responsible for the correct classification. In order to obtain this information, variance weights were calculated. Table 2 contains the largest variance weights for differentiating the $\mathrm{Mf}, \mathrm{Tr}$, and Ar samples. These weights quantify the usefulness of each characteristic in separating each pair of classes. The characteristics with the highest variance weights for separating Ar from Mf and $\mathrm{Tr}$ are located in the retention time interval of 1.65 to $1.72 \mathrm{~min}$, whereas the intervals from 2.53 to $2.60 \mathrm{~min}$ and 2.74 to 2.86 min contain the characteristics responsible for discriminating the $\mathrm{Tr}$ species from Mf and Ar. These results
Table 2 Variance weights for differentiating the three classes of the training set

\begin{tabular}{cccccc}
\hline \multicolumn{2}{c}{ Mf vs. Tr } & \multicolumn{2}{c}{ Mf vs. Ar } & \multicolumn{2}{c}{ Tr vs. Ar } \\
\hline Feature & Weight & Feature & Weight & Feature & Weight \\
\hline $1.65^{\mathrm{a}}$ & 1.61 & 1.69 & 12.89 & 1.68 & 30.81 \\
1.66 & 1.45 & 1.71 & 11.96 & 1.67 & 28.59 \\
1.67 & 1.29 & 1.68 & 11.24 & 1.69 & 25.20 \\
1.68 & 1.17 & 1.72 & 9.52 & 1.66 & 20.09 \\
1.69 & 1.10 & 1.67 & 8.16 & 1.71 & 17.33 \\
1.71 & 1.05 & 1.66 & 5.69 & 1.72 & 10.93 \\
& & & & & \\
$2.59^{\mathrm{b}}$ & 14.70 & 2.58 & 1.22 & 2.57 & 14.98 \\
2.60 & 17.38 & 2.57 & 1.21 & 2.58 & 14.94 \\
2.58 & 12.66 & 2.56 & 1.19 & 2.56 & 14.88 \\
2.57 & 9.83 & 2.59 & 1.75 & 2.59 & 14.84 \\
2.56 & 7.74 & 2.54 & 1.75 & 2.60 & 14.67 \\
2.54 & 6.61 & 2.53 & 1.16 & 2.54 & 14.51 \\
2.53 & 6.28 & 2.60 & 1.08 & 2.53 & 13.72 \\
& & & & & \\
$2.75^{\mathrm{c}}$ & 16.78 & 2.86 & 3.24 & 2.75 & 16.53 \\
2.76 & 15.60 & 2.85 & 2.97 & 2.76 & 15.64 \\
2.74 & 12.03 & 2.78 & 1.09 & 2.86 & 12.07 \\
2.77 & 11.57 & 2.77 & 1.03 & 2.77 & 12.04 \\
2.78 & 8.73 & 2.76 & 1.00 & 2.74 & 11.85 \\
2.85 & 5.79 & 2.75 & 1.00 & 2.85 & 10.75 \\
2.86 & 5.64 & 2.74 & 1.01 & 2.78 & 9.57 \\
\hline
\end{tabular}

The weights are presented in decreasing order for each retention time interval.

a. 1.65 to $1.72 \mathrm{~min}$

b. 2.53 to $2.6 \mathrm{~min}$.

c. 2.74 to $2.86 \mathrm{~min}$.

confirm that the substances responsible for this discrimination are those that present peaks at retention times around 1.7, 2.5 and $2.7 \mathrm{~min}$.

\section{Conclusion}

In this work the HPLC technique combined with the chemometric methods, SIMCA and KNN, were adequate for correctly classifying three species of Baccharis, $B$. genistelloides Persoon var. trimera (Less.) DC, B. milleflora (Less.) DC and B. articulata (Lam.) Persoon. Besides this, with the aid of PCA and variance weights it was possible to trace the chromatographic profiles of the three classes, qualitatively identifying the presence of three substances or groups of substances. With this information, the procedure can be improved to search for chemotaxonomic markers. These results show that chemometric methods associated with efficient chemical analysis methods provide powerful tools for the taxonomic characterization of morphologically similar species. The methods are reliable and conclusive and do not require analysis of specific parts of the plant during specific seasons. Furthermore, they seem to be generally applicable in situations where conventional taxonomic characterization fail.

\section{Acknowledgements}

This study had the support of the Coordenação do Pessoal de Nível Superior (CAPES/Proap). The authors would like to thank the researchers of the Laboratório de Moléculas Bioativas 
of the Departamento de Química of the Universidade Estadual de Londrina for support in the execution of the experiments. We also thank Dr. Mara Lane C. Cardoso and Dr. Leo A. Schoof and Researcher Paulo Guilherme F. Ribeiro for generously donating the plants for this study, as well as Mrs. Olinda Leites Bueno for identification of the botanical material.

\section{References}

1. L. M. B. Torres, M. T. Gamberini, N. F. Roque, M. T. Lima-Landman, C. Souccar, and A. J. Lapa, Phytochemistry, 2000, 55, 617.

2. H. P. Pedrazzi, E. R. Rodrigues, A. Zanardo Filho, and J. J. Franco, Fitoterapia, 1997, LXVIII, 26.

3. M. P. Sousa, M. E. O. Matos, F. J. A. Matos, M. I. L. Machado, and A. A. Craveiro, "Constituintes Químicos Ativos de Plantas Medicinais Brasileiras", 1991, Editora EUFC, Laboratório de Produtos Naturais, Fortaleza, Brazil, 223.

4. R. M. Gené, C. Cartañá, T. Adzet, E. Marín, T. Parella, and S. Cañigueral, Rev. Planta Médica, 1996, 62, 232.

5. N. B. Vogt, Chemom. Intell. Lab. Syst., 1987, 56, 27.

6. N. B. Perry, J. W. Van Klink, N. J. Brennan, W. Harris, R. E. Anderson, and M. H. Douglas, Phytochemistry, 1997,
45,1605

7. A. Ronse, H. De Pooter, and M. De Proft, Phytochemistry, 1997, 46, 1365.

8. S. A. V. Alvarenga, M. J. P. Ferreira, V. P. Emerenciano and D. Cabrol-Bass, Chemom. Intell. Lab. Syst., 2001, 56.

9. E. L. M. van Rosendaal, S. J. L. Kurstjenns, T. A. van Beek, and R. G. van den Berg, Phytochemistry, 1999, 52, 427.

10. J. F. Stevens, H't. Hart, E. T. Elema, and A. Bolck, Phytochemistry, 1996, 41, 503.

11. M. Kansiz, P. Heraud, B. Wood, F. Burden, J. Beardall, and D. McNaughton, Phytochemistry, 1999, 52, 407.

12. B. B. Neto, I. S. Scarminio, and R. E. Bruns, "Como fazer experimentos: pesquisa e desenvolvimento na ciência e na indústria", 2001, Editora da Unicamp, Brasil, 313 - 319.

13. R. Reyment and K. G. Jöreskog, "Applied Factor Analysis in Natural Science", 1996, Cambridge University Press, New York, 89 - 119.

14. M. A. Sharaf, D. L. Illman, and B. R. Kowalski, "Chemometric", 1986, John Wiley \& Sons, New York, 195 $-196$.

15. K. R. Beebe, R. J. Pell, and M. B. Seasholtz, "Chemometrics: A practical guide", 1998, John Wiley \& Sons, New York, $1-180$.

16. I. S. Scarminio and R. E. Bruns, Tre. Anal. Chem., 1989, 8, 8 . 